Pathophysiology

of Haemostasis and Thrombosis
Pathophysiol Haemost Thromb 2009-10;37:17-23

DOI: $\underline{10.1159 / 000315141}$
Received: January 19, 2010

Accepted after revision: March 24, 2010

Published online: May 22, 2010

\title{
Factor V Is an Anticoagulant Cofactor for Activated Protein C during Inactivation of Factor Va
}

\author{
Thomas J. Cramer John H. Griffin Andrew J. Gale \\ Department of Molecular and Experimental Medicine, The Scripps Research Institute, La Jolla, Calif., USA
}

\section{Key Words}

Anticoagulant $\cdot$ Activated protein C $\cdot$ Cofactor $\cdot$ Factor V .

Factor Va

\begin{abstract}
Coagulation factor $\mathrm{V}(\mathrm{FV})$ promotes inactivation of activated factor VIII (FVIIla) by activated protein C (APC) and protein S. Loss of this APC cofactor activity is proposed to be partially responsible for the APC resistance phenotype of $F V_{\text {Leiden. }}$. However, FVIIIla loses activity rapidly due to dissociation of the $\mathrm{A} 2$ domain, and this may be the primary mechanism of FVIIla inactivation. APC/protein S also readily inactivates activated FV (FVa). We therefore hypothesized that FV can function as an anticoagulant cofactor for APC/protein $\mathrm{S}$ in the inactivation of FVa. FV was titrated into FV-deficient plas$\mathrm{ma}$, and the APC sensitivity ratio (APCsr; a measure of APC activity) was measured in a clotting assay that was not sensitive to FVIII. Our results showed an increase in APCsr as the FV concentration increased, suggesting an anticoagulant function for $\mathrm{FV}$ in this assay. $\mathrm{FV}_{\text {Leiden }}$ showed APC resistance with an APCsr of 1.0. Therefore, under our experimental conditions, FV acted as an anticoagulant cofactor for APC in the inactivation of FVa.

Copyright $\odot 2010$ S. Karger AG, Basel
\end{abstract}

\section{Introduction}

Coagulation factor $\mathrm{V}(\mathrm{FV})$ is a critical protein in blood coagulation that circulates in the blood as a 330,000-MW monomer at a concentration of $7 \mu \mathrm{g} / \mathrm{ml}(21 \mathrm{nM})$ [1]. It has a regulatory role in both procoagulant and anticoagulant pathways. As a procoagulant, activated $\mathrm{FV}(\mathrm{FVa})$ is the nonenzymatic cofactor to activated factor $\mathrm{X}(\mathrm{FXa})$ in the activation of prothrombin to thrombin and enhances FXa proteolytic activity by several orders of magnitude. In the anticoagulant feedback loop, thrombin activates protein $\mathrm{C}$ in the thrombin-thrombomodulin complex to activated protein C (APC). Subsequently, APC inactivates procoagulant $\mathrm{FVa}$ and activated factor VIII (FVIIIa) by proteolysis, leaving them unable to act as cofactors to FXa and FIXa, respectively. Without their respective cofactors, FXa and FIXa are not significantly proteolytically active.

The known anticoagulant activity of FV consists of a cofactor function of FV for APC and protein $S$ in the inactivation of the procoagulant FVIIIa $[2,3]$. A cleavage of $\mathrm{FV}$ at $\mathrm{R} 506$ by APC is required for this cofactor function $[4,5]$, which was discovered in the analysis of APC resistance in patients with a mutant form of FV known as

\section{KARGER}

() 2010 S. Karger AG, Basel

Fax +4161306 1234

E-Mail karger@karger.ch

www.karger.com
Accessible online at: www.karger.com/pht
Andrew J. Gale

Department of Molecular and Experimental Medicine

The Scripps Research Institute, MEM-286

10550 N. Torrey Pines Road, La Jolla, CA 92037 (USA)

Tel. +1 858784 2177, Fax +1 858784 2054, E-Mail agale@ scripps.edu 
$\mathrm{FV}_{\text {Leiden. }}$. In this mutant, $\mathrm{R} 506$ is replaced by a $\mathrm{Q}$, which renders the 506 position insensitive to proteolysis by APC $\left(\mathrm{FV}_{\text {Leiden }}\right.$ is hereafter referred to as Q506-FV). Therefore, Q506-FV does not display this anticoagulant activity [4, $6,7]$. The importance of the FV cofactor activity to APC was emphasized by Castoldi et al. [8], who described that the APC resistance of Q506-FV was about 50\% due to insensitivity of Q506-FVa to APC proteolysis and about $50 \%$ due to Q506-FV lacking APC cofactor activity for the inactivation of FVIIIa.

Apart from proteolysis by APC, FVIIIa is also inactivated by spontaneous dissociation of its A2 domain, which gives FVIIIa a half-life of approximately $2 \mathrm{~min}$ in plasma [9]. Because of this rapid loss of the A2 domain, it has been argued that this is the primary method by which FVIIIa is inactivated in vivo, suggesting APC-mediated inactivation to be of lesser physiological relevance $[10,11]$. We therefore hypothesized that since Q506-FV is a known risk factor for thrombosis, $\mathrm{FV}$ is also an anticoagulant cofactor for APC in the inactivation of FVa.

APC cleaves FVa at positions R306, R506 and R679, of which the cleavage at R506 occurs the fastest and that at R679 the slowest [12]. Cleavage at R306 causes dissociation of the A2 domain from the FVa molecule, resulting in total loss of activity in the prothrombinase complex $[12,13]$. Cleavage at R506, however, results in a partially active intermediate $[12,14]$.

To test our hypothesis, we investigated FV anticoagulant activity in a plasma-based clotting assay that is sensitive to FV but insensitive to FVIII. FV clearly prolonged clotting time in the presence of APC, suggesting that the presence of $\mathrm{FV}$ enhanced $\mathrm{FVa}$ inactivation.

\section{Materials and Methods}

Protein S, human fibrinogen, FX, prothrombin and thrombin were from Enzyme Research Laboratories (South Bend, Ind., USA). APC and plasma-derived FV were from Haematologic Technologies (Essex Junction, Vt., USA); plasma-derived FV from Haematologic Technologies is referred to as plasma-derived wildtype (WT)-FV in this paper. Recombinant full-length FVIII was a gift from Bayer Corporation (Berkeley, Calif., USA). Bovine brain phosphatidylserine and bovine brain phosphatidylethanolamine were from Sigma (St. Louis, Mo., USA). Bovine liver phosphatidylcholine was from Avanti Polar Lipids (Alabaster, Ala., USA). Bovine serum albumin (BSA) was from Calbiochem/EMD Biosciences (La Jolla, Calif., USA). M662C/D1828C-FVIII was characterized previously $[15,16]$. FV-deficient plasma was from Affinity Biologicals (Ancaster, Ont., Canada). FVIII-deficient plasma and normal pooled human plasma were from George King Biomedical Inc. (Overland Park, Kans., USA). Platelin LS activated partial thromboplastin time (APTT) reagent was from
Trinity Biotech LPC (Bray, Wicklow, Ireland). FVIII-specific human IgG monoclonal antibody BO2C11 [17] was a generous gift from Dr. Marc Jacquemin (University of Leuven, Leuven, Belgium). The chromogenic substrate $\mathrm{H}-\mathrm{D}$-cyclohexylglycine-AlaArg-paranitroanilide (Pefachrome $\mathrm{TH}$ ) was from Centerchem Inc. (Norwalk, Conn., USA). Benzamidine and D-Phe-Pro-Arg chloromethyl ketone were from Calbiochem. Phenylmethanesulfonyl fluoride was from Sigma.

Phospholipid Vesicles

Phospholipid vesicles composed of $40 \%$ phosphatidylcholine, $20 \%$ phosphatidylserine and $40 \%$ phosphatidylethanolamine (M/M/M) (PCPSPE) were prepared as described previously [18].

\section{Recombinant FV Mutant Preparations}

Ser2183Ala B domain-deleted FV was produced as described elsewhere [13]. In this FV variant, the segment $812-1491$ of the B domain is absent, and it will be referred to as WT-FV throughout this paper. Site-directed mutagenesis was used to generate the R506Q mutant of this FV. The cDNAs for these FV variants were inserted into the expression vector pED [19] and transfected into modified BHK cells (a kind gift from Dr. Rodney Camire, Philadelphia, Pa., USA) together with the plasmid pRSVneo for selection with geneticin. FV was purified from conditioned medium via precipitation with $16 \%$ polyethylene glycol 6000 , followed by binding to an anti-FV light chain monoclonal antibody column (AHV5101-Sepharose, AHV5101 from Haematologic Technologies) as described elsewhere [13, 20].

\section{Dilute Prothrombin Time Clotting Assay}

All clotting assays were performed with a STart ${ }^{\circledR} 4$ semiautomated hemostasis analyzer from Diagnostica Stago (Parsippany, N.J., USA). Plasma was diluted $5 \times$ in HBS-0.5\% BSA (pH 7.4) and supplemented with $1 \mathrm{mg} / \mathrm{ml}$ human fibrinogen and $75 \mu \mathrm{M}$ PCPSPE (40:20:40) phospholipid vesicles. Either FV or FVIII was then added to the plasma mix, after which APC or HBS- $0.5 \%$ BSA was added and the mix was kept at $37^{\circ} \mathrm{C}$ for $3 \mathrm{~min}$. Clotting was initiated by Dade ${ }^{\circledR}$ Innovin (Siemens Healthcare Diagnostics Inc., Deerfield, Ill., USA) diluted in recalcification buffer (HBS, $0.5 \%$ BSA, $12.5 \mathrm{mM} \mathrm{CaCl}_{2}, \mathrm{pH}$ 7.4). The final reaction volume was 150 $\mu \mathrm{l}$, and final concentrations were as follows: $15 \times$ diluted plasma, $25 \mu \mathrm{M}$ PCPSPE phospholipid vesicles, $0.33 \mathrm{mg} / \mathrm{ml}$ human fibrinogen, $4.5 \mathrm{nM}$ APC, $180 \times$ diluted Innovin and approximately $4 \mathrm{~mm}$ free $\mathrm{Ca}^{2+}$. Other reagents were at the concentrations indicated in the text.

\section{APTT Assay}

A volume of $50 \mu \mathrm{l}$ of plasma was mixed with $50 \mu \mathrm{l}$ of Platelin LS APTT reagent and incubated at $37^{\circ} \mathrm{C}$ for $3 \mathrm{~min}$. Clotting was initiated by addition of $50 \mu \mathrm{l}$ of recalcification buffer (HBS- $0.5 \%$ BSA-25 $\mathrm{mM} \mathrm{CaCl}_{2}, \mathrm{pH} 7.4$ ).

\section{Results}

To investigate a possible FV cofactor effect in FVa inactivation by APC, we designed a clotting assay that was sensitive to FV but was insensitive to FVIII (a dilute pro- 

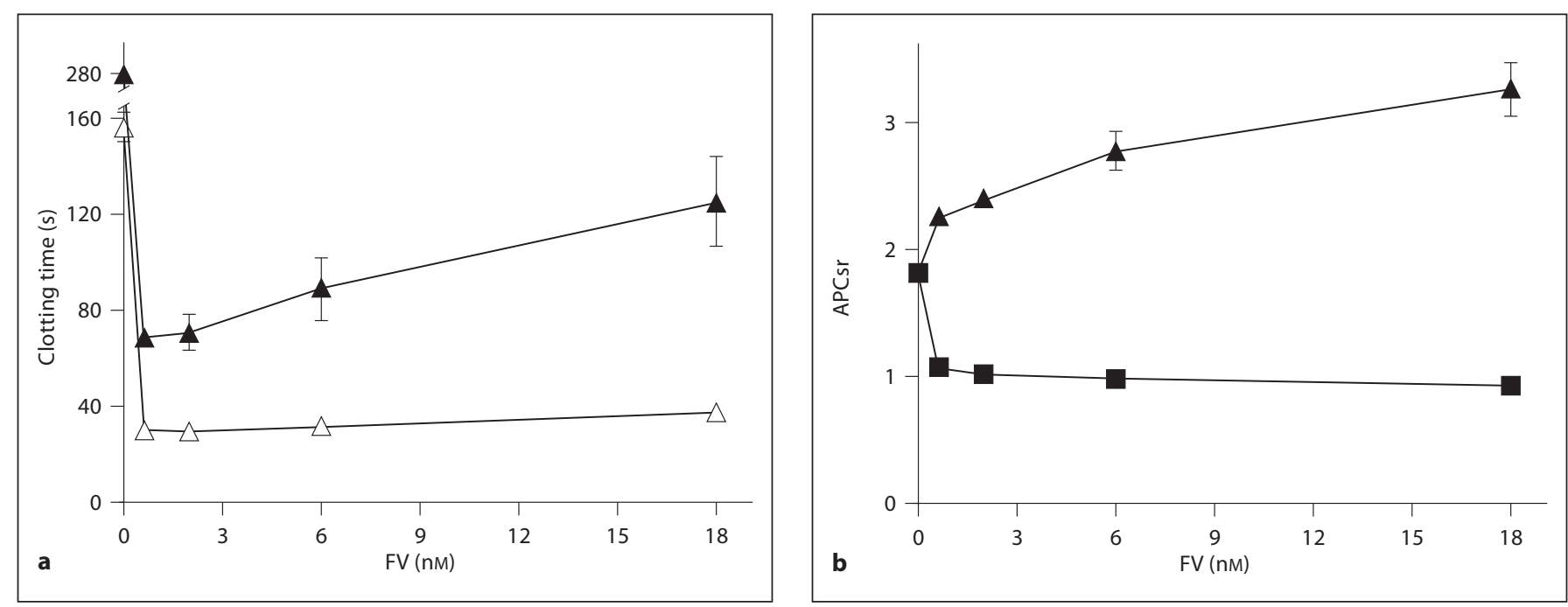

Fig. 1. FV titrations in FV-deficient plasma in the dilute prothrombin time clotting assay. a, c Clotting time in seconds of WT-FV (a) and Q506-FV (c) titrations in the absence $(\triangle, \square)$ and presence $(\boldsymbol{\Lambda}, \boldsymbol{\square})$ of APC. b APCsr of WT-FV $(\boldsymbol{\Delta})$ and Q506-FV (a). $\mathrm{n}=5$. Error bars represent the SEM.

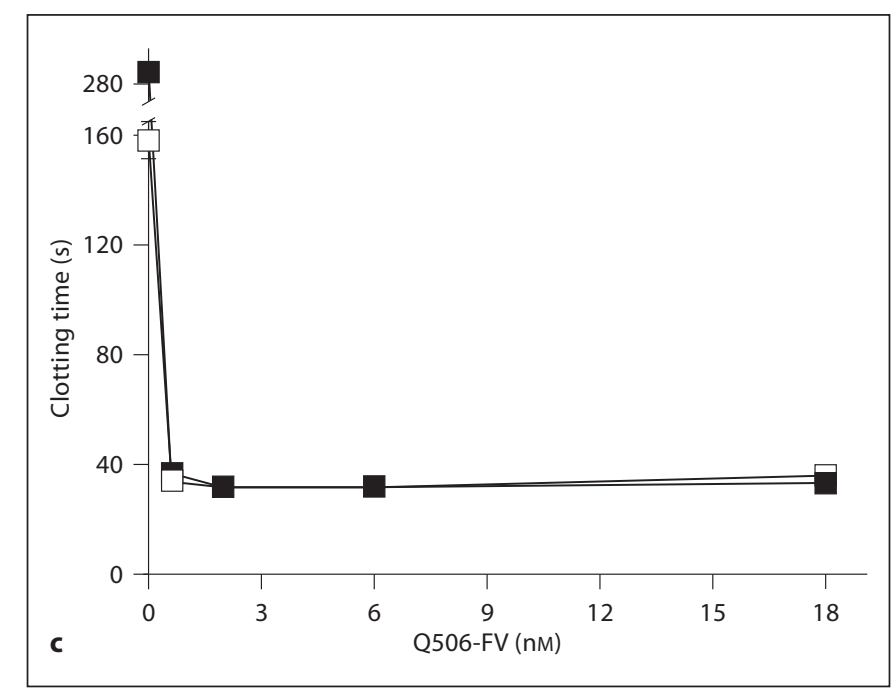

thrombin time clotting assay). FV was titrated at final concentrations from 0 to $18 \mathrm{nM}$ into this assay using FVdeficient plasma, and clotting time was measured in the absence or the presence of $4.5 \mathrm{nM}$ APC. We used this assay to monitor APC activity with an APC sensitivity ratio (APCsr), which was calculated by dividing clotting time in the presence of APC by clotting time in the absence of APC. An increase in APCsr indicates an increase in APC anticoagulant activity, and a ratio of 1.0 indicates no APC anticoagulant activity.

Actual clotting times of FV titrations are shown in figure 1a (WT-FV) and 1c (Q506-FV). In the absence of any FV, clotting times were very long, approximately $160 \mathrm{~s}$ without APC and approximately $280 \mathrm{~s}$ in the presence of APC. However, at the lowest concentration of FV

(0.7 nM), clotting times in the absence of APC decreased to a plateau at approximately $35 \mathrm{~s}$.

Titrations of WT-FV revealed an increase in clotting time in the presence of APC as the FV concentration increased (fig. 1a), indicating an increase in APC activity. However, as mentioned above, clotting times plateaued at $35 \mathrm{~s}$ in the absence of APC. Therefore, the APCsr increased as the FV concentration increased, from a ratio of 1.7 when no FV was added to 3.3 at $18 \mathrm{nM}$ FV (fig. 1b). These experiments were performed with B domain-deleted FV [13] in order to enable direct comparison between WT and recombinant mutant Q506$\mathrm{FV}$, but similar results were obtained using plasma-derived WT-FV (data not shown). Thorelli et al. [21] already confirmed that a similar B domain-deleted FV 


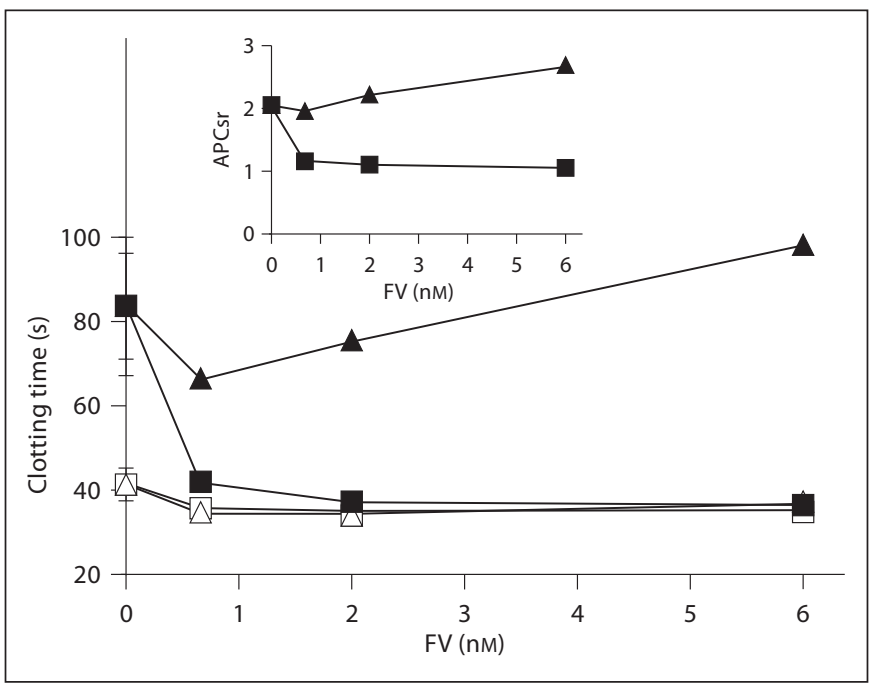

Fig. 2. FV titrations in FV-deficient plasma in the presence of $2 \mathrm{nM} \mathrm{FVa}$ in the dilute prothrombin time clotting assay. Clotting time in seconds of WT-FV $(\boldsymbol{\Delta}, \triangle)$ and Q506-FV $(\boldsymbol{\square}, \square)$ titrations in the absence $(\triangle, \square)$ and presence $(\boldsymbol{\Lambda}, \boldsymbol{\square})$ of APC. Inset: APCsr. $\mathrm{n}=2$. Error bars represent the SEM.

variant was capable of APC cofactor activity during FVIIIa inactivation. In addition, since the plasma and therefore the protein $S$ are diluted in this assay, we also performed this FV titration in the presence of $40 \mathrm{nM}$ additional protein $S$. The results were essentially the same (data not shown). These data suggest that FV functioned as an anticoagulant cofactor to APC during the inactivation of FVa.

Mutation of FV at R506 to Q abolishes APC cofactor activity for FVIIIa inactivation since APC cleavage at $\mathrm{R} 506$ in FV is required for APC cofactor activity [4]. Unlike WT-FV, Q506-FV did not cause an increase in clotting time at higher FV concentrations in the presence of APC (fig. 1c). This resulted in an APCsr of approximately 1 over the whole concentration range of Q506-FV. Therefore, as was the case for FVIIIa inactivation, Q506FV did not show cofactor activity for APC in the inactivation of FVa.

In order to confirm that procoagulant FVa was present in these clotting assays with FV titrations, these assays were also performed in the presence of $2 \mathrm{nM}$ WT-FVa. This concentration of FVa gave a clotting time of approximately $40 \mathrm{~s}$ in the absence of any added FV. Addition of the lowest concentration of WT or Q506-FV decreased the clotting time by only a few seconds further, and higher concentrations of FV had no further effect in the absence of APC (fig. 2). WT-FV or Q506-FV were titrated up to $6 \mathrm{nM}$, and, as before, an increase in WT-FV caused an increase in clotting time in the presence of APC, with the APCsr ranging from 2 to 2.6. Increasing concentrations of Q506-FV had no impact on clotting time, thus generating an APCsr of 1 throughout the concentration range. These data demonstrated that FVa was present in the assays in figure 1, and that in the presence of $\mathrm{FVa}$, WT-FV still showed an anticoagulant effect when APC was present.

Because FV is a cofactor for APC in the inactivation of FVIIIa, we performed a variety of controls to confirm that the dilute prothrombin time clotting assay was not sensitive to FVIII or to FVIIIa inactivation. The FVIIIspecific human IgG monoclonal antibody BO2C11 [17] was used to block FVIII procoagulant activity. Normal plasma was incubated with $\mathrm{BO} 2 \mathrm{C} 11$ and then assayed in the dilute prothrombin time clotting assay or in a standard APTT assay. In the latter, the antibody prolonged clotting time approximately 2-fold, whereas $\mathrm{BO} 2 \mathrm{C} 11$ had no effect on the dilute prothrombin time clotting assay (fig. 3a). The FVIII-inhibitory function of BO2C11 was confirmed with purified proteins in a factor Xase assay (data not shown).

$\mathrm{BO} 2 \mathrm{C} 11$ was then used to block FVIII activity in a repeat of the $\mathrm{FV}$ titrations as performed in figure $1 . \mathrm{BO} 2 \mathrm{C} 11$ had no effect on the clotting times or on the APCsr (fig. 3b). Additionally, FVIII-deficient plasma had a normal clotting time in the dilute prothrombin time assay (fig. 3c, no APC zero point), and titrating FVIII into FVIII-deficient plasma had no effect on this clotting time either in the absence or the presence of APC, even though APC did prolong the clotting time to $>80 \mathrm{~s}$ (fig. 3c). This experiment was also performed with fulllength WT-FVIII and in the presence of the $\mathrm{BO} 2 \mathrm{C} 11$ antibody, neither of which had any effect on clotting time in FVIII-deficient plasma (data not shown). Controls using normal human plasma in the dilute prothrombin time clotting assay and the APTT assay showed that the amount of time that $\mathrm{BO} 2 \mathrm{C} 11$ was preincubated with the plasma did not itself influence the clotting times (data not shown). However, as shown, this assay was very sensitive to $\mathrm{FV}$, and clotting times were greatly prolonged in the absence of any FV (fig. 1, 2). At these greatly prolonged clotting times in FV-deficient plasma, a small procoagulant effect was observed at extremely high FVIII concentrations. Clotting time ranged from $160 \mathrm{~s}$ when no FVIII was added to $140 \mathrm{~s}$ at $8 \mathrm{U} / \mathrm{ml}$ FVIII (fig. 3d). This effect was more pronounced in the presence of APC, with clotting times ranging from $290 \mathrm{~s}$ when no FVIII was added to $190 \mathrm{~s}$ at $8 \mathrm{U} / \mathrm{ml}$ FVIII. This 

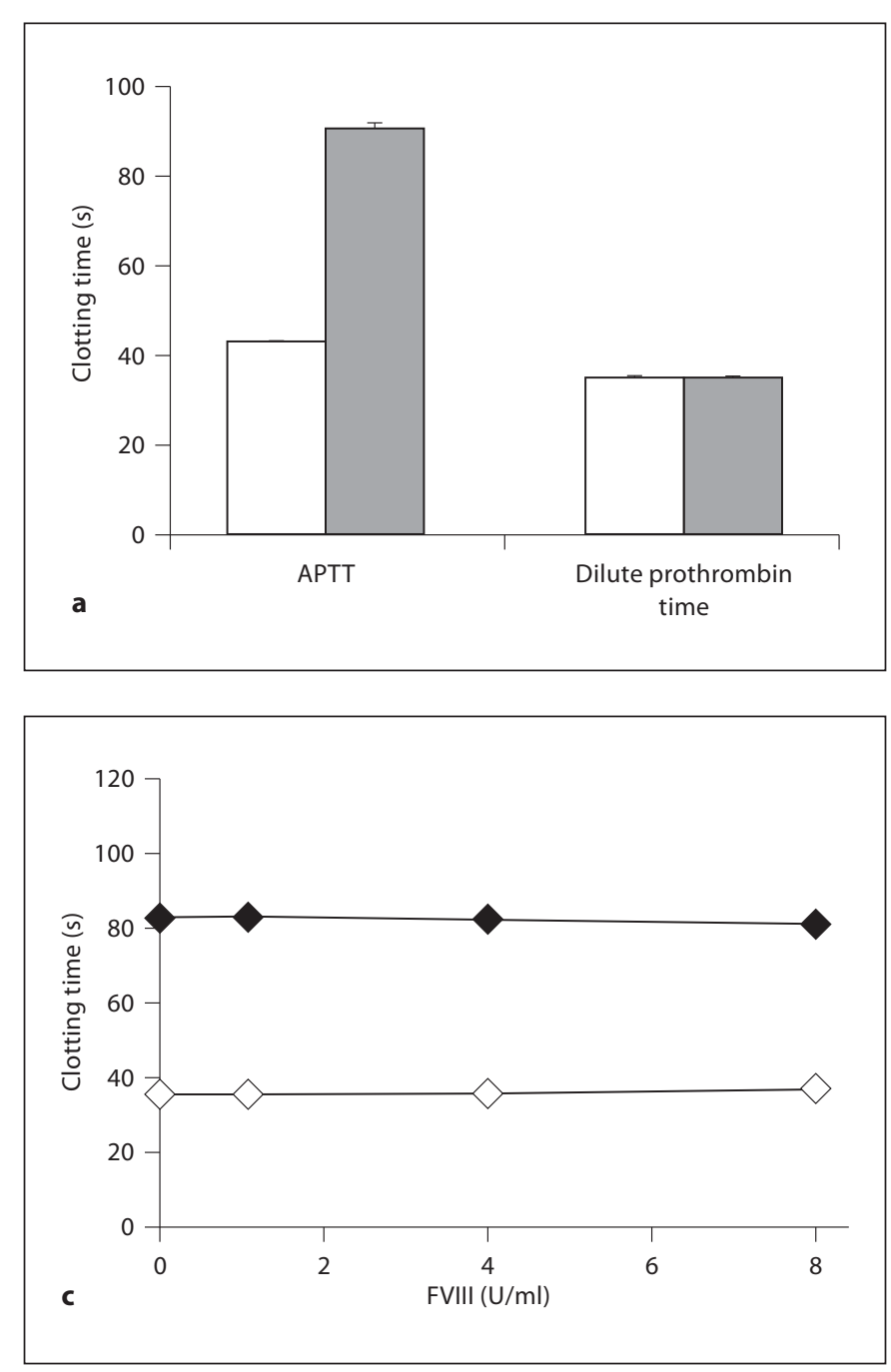

Fig. 3. Control experiments for FVIII sensitivity of the dilute prothrombin time clotting assay. a Pooled normal human plasma was incubated in the absence or presence of $1 \mu \mathrm{g} / \mathrm{ml} \mathrm{BO} 2 \mathrm{C} 11$ for $2 \mathrm{~h}$ at $37^{\circ} \mathrm{C}$ and then used in the APTT assay and dilute prothrombin time clotting assay. $\mathrm{n}=4$. Error bars represent the SEM. b FVdeficient plasma was incubated in the absence $(\boldsymbol{\Lambda}, \triangle$ ) or presence $(\bullet, \bigcirc)$ of $20 \mu \mathrm{g} / \mathrm{ml} \mathrm{BO} 2 \mathrm{C} 11$ for $80 \mathrm{~min}$ at $37^{\circ} \mathrm{C}$ and then used in FV titrations, in the absence $(\triangle, \bigcirc)$ or presence $(\boldsymbol{\Delta}, \boldsymbol{\theta})$ of APC. Inset: APCsr. Final concentration of BO2C11 was $1.3 \mu \mathrm{g} / \mathrm{ml}$.

indicates that this assay is somewhat sensitive to FVIII only in the complete absence of FV when clotting times are greatly prolonged. From the data presented in figure 3, we concluded that the dilute prothrombin time clotting assay was not sensitive to FVIII under our experimental conditions.

Anticoagulant Activity of Factor V
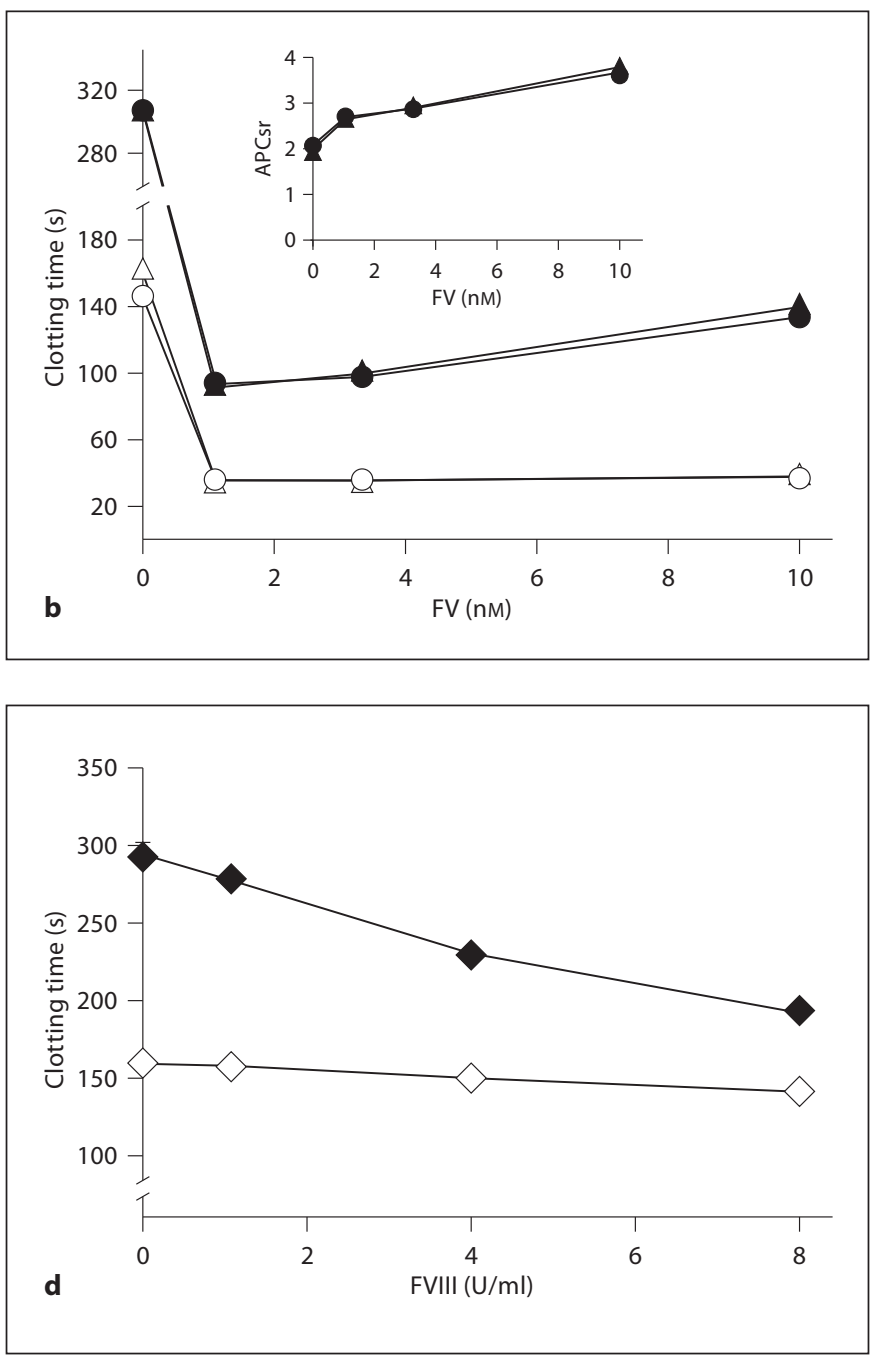

$\mathrm{n}=1$. c M662C/D1828C-FVIII was titrated in FVIII-deficient plasma and clotting time was measured in the absence $(\diamond)$ or presence $($ ) of APC. $\mathrm{n}=1$. d M662C/D1828C-FVIII was titrated in $\mathrm{FV}$-deficient plasma and clotting time was measured in the absence $(\diamond)$ or presence $(\checkmark)$ of APC. The FVIII concentration for each data point represents total FVIII present in the final reaction, which included added FVIII plus $0.067 \mathrm{U} / \mathrm{ml} \mathrm{FVIII} \mathrm{present} \mathrm{in} 15$ fold diluted FV-deficient plasma. $\mathrm{n}=1$.

\section{Discussion}

In this study, we have shown an anticoagulant effect of FV as a cofactor for APC as measured in a clotting assay sensitive to FV activity. We have excluded that this assay was sensitive to FVIII. An inhibitory monoclonal antibody directed against FVIII (BO2C11) did not affect the clotting time in the FV titrations in FV-deficient plas- 
ma. Furthermore, FVIII titrations into FVIII-deficient plasma using the same experimental settings did not change clotting time. Only in the absence of FV (FVIII titration into FV-deficient plasma) was a concentrationdependent effect of FVIII observed, but only at very high concentrations of FVIII.

Castoldi et al. [8] previously illustrated the importance of FV cofactor activity for APC in the inactivation of FVIIIa, using plasma-based assays that were sensitive to either both FVa and FVIIIa or FVIIIa alone. In this earlier study, an anticoagulant effect of FV was also shown in thrombin generation assays, under conditions where both FVIIIa and FVa activity were measured. It was assumed, however, that only FVIIIa inactivation by APC/ protein $\mathrm{S}$ was enhanced by FV and not FVa inactivation. In the present study, we isolated FVa activity and observed that FV did enhance FVa inactivation. Thus, our results complement and extend the findings of Castoldi et al. [8] and suggest that the anticoagulant effect of FV on FVa inactivation may have also played a role in their study.

The effect of FV on FVa inactivation suggests a role for $\mathrm{FV}$ as an anticoagulant in normal homeostasis. One purpose of this effect of FV on FVa inactivation may be to prevent blood from reaching a clotting threshold by enhancing the inactivation of trace FVa that is formed while the FV concentration is high. Furthermore, FV may help APC localize and limit clot formation since, under flow, fresh blood with normal levels of FV would flow over the site of active coagulation.

Inactivation of FVIIIa by APC takes place via cleavages at R336 and R562. The latter is the slower cleavage and is required for full inactivation of the FVIIIa molecule. Our lab has recently shown that FV enhanced cleavage at both R336 and R562 in FVIIIa, but cleavage at R562 was enhanced to a greater extent than cleavage at R336 [22]. It is therefore possible that FV as cofactor for APC will show a similar pattern in the inactivation of $\mathrm{FVa}$, namely a greater stimulation of R306 cleavage than R506 cleavage. In support of this, the APCsr dropped to 1 in the Q506-FV titrations (fig. 1, 2), which suggests that Q506-FVa was not significantly inactivated by APC. This could result from reduced cleavage at R306 in Q506-FVa when the FV cofactor function is absent. However, further studies will be required to elucidate which cleavage in FVa the FV anticoagulant effect is directed towards.

There are other factors present in plasma that may affect the FV anticoagulant effect on FVa inactivation. Both prothrombin and FXa are known to protect FVa from proteolysis by APC $[23,24]$. Recently, these interactions have been characterized in more detail $[25,26]$. FXa inhibits cleavage of R506 by APC, which is partly reversed by protein S. However, cleavage at R306 is stimulated by FXa, which was shown to be additive to the stimulatory effect of protein $\mathrm{S}$ for cleavage at this site. Prothrombin protects both R306 and R506 from cleavage by APC, and here also protein S partially alleviates the protection. It is possible that FV further abrogates the protection by FXa and/or prothrombin, but further research will be required to determine if these factors play a role in the FV cofactor effect of APC-mediated FVa inactivation.

In conclusion, we have observed an anticoagulant effect of FV in a clotting assay that was sensitive to only FVa inactivation by APC. Therefore, we propose that FV acts as an anticoagulant cofactor for APC in the inactivation of both FVa and FVIIIa.

\section{Acknowledgements}

The authors would like to thank Drs. Marc Jaquemin and Rodney Camire for gifts of reagents. This work was supported in part by NIH grants R01HL082588 (A.J. Gale) and R01HL052246 (J.H. Griffin). T.J. Cramer was supported by the Stein Endowment Fund.

\section{References}

$>_{1}$ Tracy PB, Eide LL, Bowie EJ, Mann KG: Radioimmunoassay of factor $\mathrm{V}$ in human plasma and platelets. Blood 1982;60:59-63.

2 Dahlbäck B, Hildebrand B: Inherited resistance to activated protein $\mathrm{C}$ is corrected by anticoagulant cofactor activity found to be a property of factor V. Proc Natl Acad Sci USA 1994;91:1396-1400.
- 3 Shen L, Dahlback B: Factor V and protein S as synergistic cofactors to activated protein $\mathrm{C}$ in degradation of factor VIIIa. J Biol Chem 1994;269:18735-18738.

4 Thorelli E, Kaufman RJ, Dahlback B: Cleavage of factor $\mathrm{V}$ at Arg 506 by activated protein $\mathrm{C}$ and the expression of anticoagulant activity of factor V. Blood 1999;93:25522558.
${ }_{5}$ Lu D, Kalafatis M, Mann KG, Long GL: Comparison of activated protein C/protein $\mathrm{S}$-mediated inactivation of human factor VIII and factor V. Blood 1996;87:4708-4717.

- 6 Bertina RM, Koeleman BP, Koster T, Rosendaal FR, Dirven RJ, de Ronde H, van der Velden PA, Reitsma PH: Mutation in blood coagulation factor $\mathrm{V}$ associated with resistance to activated protein C. Nature 1994; 369:64-67. 
7 Greengard JS, Sun X, Xu X, Fernandez JA, Griffin JH, Evatt B: Activated protein C resistance caused by Arg506Gln mutation in factor Va. Lancet 1994;343:1361-1362.

$\checkmark 8$ Castoldi E, Brugge JM, Nicolaes GA, Girelli D, Tans G, Rosing J: Impaired APC cofactor activity of factor $\mathrm{V}$ plays a major role in the APC resistance associated with the factor $\mathrm{V}$ Leiden (R506Q) and R2 (H1299R) mutations. Blood 2004;103:4173-4179.

-9 Lollar P, Parker ET: Structural basis for the decreased procoagulant activity of human factor VIII compared to the porcine homolog. J Biol Chem 1991;266:12481-12486.

10 Pipe SW, Eickhorst AN, McKinley SH, Saenko EL, Kaufman RJ: Mild hemophilia A caused by increased rate of factor VIII A2 subunit dissociation: evidence for nonproteolytic inactivation of factor VIIIa in vivo. Blood 1999;93:176-183.

11 Fay PJ: Regulation of factor VIIIa in the intrinsic factor Xase. Thromb Haemost 1999; 82:193-200.

12 Kalafatis M, Rand MD, Mann KG: The mechanism of inactivation of human factor $\mathrm{V}$ and human factor Va by activated protein C. J Biol Chem 1994;269:31869-31880.

-13 Gale AJ, Xu X, Pellequer JL, Getzoff ED, Griffin JH: Interdomain engineered disulfide bond permitting elucidation of mechanisms of inactivation of coagulation factor Va by activated protein C. Protein Sci 2002; 11:2091-2101.
14 Nicolaes GA, Tans G, Thomassen MC, Hemker HC, Pabinger I, Varadi K, Schwarz HP, Rosing J: Peptide bond cleavages and loss of functional activity during inactivation of factor Va and factor VaR506Q by activated protein C. J Biol Chem 1995;270:2115821166.

15 Gale AJ, Pellequer JL: An engineered interdomain disulfide bond stabilizes human blood coagulation factor VIIIa. J Thromb Haemost 2003;1:1966-1971.

16 Gale AJ, Radtke KP, Cunningham MA, Chamberlain D, Pellequer JL, Griffin JH: Intrinsic stability and functional properties of disulfide bond-stabilized coagulation factor VIIIa variants. J Thromb Haemost 2006;4: 1315-1322.

17 Jacquemin MG, Desqueper BG, Benhida A, Vander EL, Hoylaerts MF, Bakkus M, Thielemans K, Arnout J, Peerlinck K, Gilles JG, Vermylen J, Saint-Remy JM: Mechanism and kinetics of factor VIII inactivation: study with an IgG4 monoclonal antibody derived from a hemophilia A patient with inhibitor. Blood 1998;92:496-506.

18 Mesters RM, Houghten RA, Griffin JH: Identification of a sequence of human activated protein C (residues 390-404) essential for its anticoagulant activity. J Biol Chem 1991;266:24514-24519.

19 Kaufman RJ, Davies MV, Wasley LC, Michnick D: Improved vectors for stable expression of foreign genes in mammalian cells by use of the untranslated leader sequence from EMC virus. Nucleic Acids Res 1991;19:44854490.
20 Heeb MJ, Rehemtulla A, Moussalli M, Kojima Y, Kaufman RJ: Importance of individual activated protein $\mathrm{C}$ cleavage site regions in coagulation factor $\mathrm{V}$ for factor Va inactivation and for factor Xa activation. Eur J Biochem 1999;260:64-75.

21 Thorelli E, Kaufman RJ, Dahlback B: The Cterminal region of the factor $\mathrm{V}$ B-domain is crucial for the anticoagulant activity of factor V. J Biol Chem 1998;273:16140-16145.

-22 Gale AJ, Cramer TJ, Rozenshteyn D, Cruz JR: Detailed mechanisms of the inactivation of factor VIIIa by activated protein $\mathrm{C}$ in the presence of its cofactors, protein $\mathrm{S}$ and factor V. J Biol Chem 2008;283:16355-16362.

23 Mitchell CA, Jane SM, Salem HH: Inhibition of the anticoagulant activity of protein $\mathrm{S}$ by prothrombin. J Clin Invest 1988;82:21422147.

24 Rosing J, Hoekema L, Nicolaes GAF, Thomassen MCLGD, Hemker HC, Varadi K, Schwarz HP, Tans G: Effects of protein S and factor Xa on peptide bond cleavages during inactivation of factor $\mathrm{Va}$ and factor VaR506Q by activated protein C. J Biol Chem 1995;270: 27852-27858.

25 Norstrom EA, Tran S, Steen M, Dahlback B: Effects of factor $\mathrm{Xa}$ and protein $\mathrm{S}$ on the individual activated protein $\mathrm{C}$-mediated cleavages of coagulation factor Va. J Biol Chem 2006;281:31486-31494.

26 Tran S, Norstrom E, Dahlback B: Effects of prothrombin on the individual activated protein $\mathrm{C}$-mediated cleavages of coagulation factor Va. J Biol Chem 2008;283:6648-6655. 